Case Report

\title{
Fatal Nonhepatic Hyperammonemia in ICU Setting: A Rare but Serious Complication following Bariatric Surgery
}

\author{
Gyanendra Acharya, ${ }^{1}$ Sunil Mehra, ${ }^{2}$ Ronakkumar Patel, ${ }^{1}$ \\ Simona Frunza-Stefan, ${ }^{1}$ and Harmanjot Kaur ${ }^{3}$ \\ ${ }^{1}$ Department of Internal Medicine, Wyckoff Heights Medical Center, Brooklyn, NY 11237, USA \\ ${ }^{2}$ Division of Pulmonary and Critical Care Medicine, Department of Internal Medicine, Wyckoff Heights Medical Center, \\ Brooklyn, NY 11237, USA \\ ${ }^{3}$ Department of Medical Education, Wyckoff Heights Medical Center, Brooklyn, NY 11237, USA
}

Correspondence should be addressed to Gyanendra Acharya; achgyanen@hotmail.com

Received 3 January 2016; Accepted 15 March 2016

Academic Editor: Gerhard Pichler

Copyright (C) 2016 Gyanendra Acharya et al. This is an open access article distributed under the Creative Commons Attribution License, which permits unrestricted use, distribution, and reproduction in any medium, provided the original work is properly cited.

Bariatric surgery is well established in reducing weight and improving the obesity-associated morbidity and mortality. Hyperammonemic encephalopathy following bariatric surgery is rare but highly fatal if not diagnosed in time and managed aggressively. Both macro- and micronutrients deficiencies play a role. A 42-year-old Hispanic female with a history of Roux-en-Y Gastric Bypass Procedure was brought to ED for progressive altered mental status. Physical exam was remarkable for drowsiness with Glasgow Coma Scale 11, ascites, and bilateral pedal edema. Labs showed elevated ammonia, low hemoglobin, low serum prealbumin, albumin, HDL, and positive toxicology. She remained obtunded despite the treatment with Narcan and flumazenil and the serum ammonia level fluctuated despite standard treatment with lactulose and rifaximin. Laboratory investigations helped to elucidate the etiology of the hyperammonemia most likely secondary to unmasking the functional deficiency of the urea cycle enzymes. Hyperammonemia in the context of normal liver function tests becomes diagnostically challenging for physicians. Severe hyperammonemia is highly fatal. Early diagnosis and aggressive treatment can alter the prognosis favorably.

\section{Introduction}

Bariatric surgery is well established in reducing weight and improving obesity-associated morbidity and mortality. Neurological complication such as hyperammonemic encephalopathy following bariatric surgery is rare but highly fatal if not diagnosed and treated aggressively on time. Both macro- and micronutrients deficiencies seem to play an important role in unmasking the functional deficiency of urea cycle enzymes in an adult woman after bariatric surgery.

\section{Case Presentation}

A 42-year-old Hispanic female was brought to ED with complaint of progressive altered mental status over the past few days. At ED, the patient was only responsive to painful stimuli but did not appear in acute distress. Her mother, who provided the history, had a conversation with patient three hours prior to the presentation to ED. Patient had decreased oral food intake for the last two weeks. She denied history of fever or illicit drug use except for prescribed medications. Patient had Roux-en-Y Gastric Bypass Surgery (RYGBS) two years ago for morbid obesity and gastrojejunal stent placement procedure two weeks prior to the presentation. Her medications were oral vitamins, dilaudid $4 \mathrm{mg}$, amitriptyline, and zolpidem.

Physical examinations were remarkable for drowsiness with Glasgow Coma Scale (GCS) 11, ascites, and bilateral pitting pedal edema. Vital signs were within normal range. Initial labs (Table 1) were remarkable for hemoglobin (5.4 gm\%), INR (2.15), aPTT $(67.5 \mathrm{sec})$, BUN $(11 \mathrm{mg} / \mathrm{dL})$, creatinine $(2.1 \mathrm{mg} / \mathrm{dL})$, AST $(49 \mathrm{IU} / \mathrm{L})$ and ALT $(23 \mathrm{IU} / \mathrm{L})$, CPK (466 IU/L), low HDL cholesterol $(<5 \mathrm{mg} / \mathrm{dL})$, and prealbumin $(<5 \mu \mathrm{g} / \mathrm{dL})$ and albumin $(1.8 \mathrm{~g} / \mathrm{dL})$, and arterial blood 
TABLE 1: Basic laboratory investigations.

\begin{tabular}{lcc}
\hline Lab. test & Results & Ref. range \\
\hline WBC & 8.34 & $4.5-10.9 \mathrm{k} / \mu \mathrm{L}$ \\
Hb & $\mathbf{5 . 4}$ & $12.5-15.0 \mathrm{~g} / \mathrm{dL}$ \\
Platelets & 116 & $130-400 \mathrm{k} / \mu \mathrm{L}$ \\
Sodium & 136 & $135-145 \mathrm{mmol} / \mathrm{L}$ \\
Potassium & 4.8 & $3.6-5.2 \mathrm{mmol} / \mathrm{L}$ \\
BUN & $\mathbf{1 1}$ & $6-21 \mathrm{mg} / \mathrm{dL}$ \\
Creatinine & $\mathbf{2 . 1}$ & $0.6-1.1 \mathrm{mg} / \mathrm{dL}$ \\
Glucose & 113 & $70-140 \mathrm{mg} / \mathrm{dL}$ \\
INR & $\mathbf{2 . 1 5}$ & $0.8-1.2$ \\
aPTT & $\mathbf{6 7 . 5}$ & $28-38 \mathrm{sec}$ \\
CPK & $\mathbf{4 6 6}$ & $22-198 \mathrm{IU} / \mathrm{L}$ \\
AST & $\mathbf{4 9}$ & $13-40 \mathrm{IU} / \mathrm{L}$ \\
ALT & $\mathbf{2 3}$ & $17-35 \mathrm{IU} / \mathrm{L}$ \\
ALP & 116 & $37-130 \mathrm{U} / \mathrm{L}$ \\
Albumin & $\mathbf{1 . 8}$ & $3.5-5.0 \mathrm{~g} / \mathrm{dL}$ \\
Prealbumin & $<5$ & $20-40 \mu \mathrm{g} / \mathrm{dL}$ \\
HDL & $<\mathbf{5}$ & $>50 \mathrm{mg} / \mathrm{dL}$ \\
LDL & 95 & $<100 \mathrm{mg} / \mathrm{dL}$ \\
TG & 133 & $<150 \mathrm{mg} / \mathrm{dL}$ \\
S. NH ${ }_{3}^{+}$ & $\mathbf{1 9 3}$ & $<30 \mu \mathrm{mol} / \mathrm{L}$ \\
P. zinc & $\mathbf{2 3}$ & $60-130 \mu \mathrm{g} / \mathrm{dL}$ \\
S. copper & 57 & $70-175 \mu \mathrm{g} / \mathrm{dL}$ \\
24 hr U. Cu & 25 & $15-60 \mu \mathrm{g} / 24 \mathrm{hr}$ \\
Valproate & $<1.0$ & $50-100 \mu \mathrm{g} / \mathrm{mL}$ \\
Lithium & & $0.8-1.2 \mathrm{mmol} / \mathrm{L}$ \\
\hline WBC: white blood cells; Hb: hemoglobin; BUN: blood urea nitrogen; \\
PT: prothrombin time; INR: international normalized ratio; aPTT: acti- \\
vated partial thrombin time; CPK: creatinine phosphokinase; AST/ALT: \\
aspartate/alanine aminotransferase; ALP: alkaline phosphatase; HDL: high- \\
density lipoprotein; LDL: low-density lipoprotein; TG: triglycerides; P.: \\
plasma; S.: serum. & & \\
& &
\end{tabular}

gas (ABG) demonstrated PH 7.39. Computed tomography (CT) of the head was unremarkable (Figure 1(a)). EKG shows sinus rhythm. She was empirically treated with Narcan and flumazenil with an impression of prescription drugs overdose as urine toxicology was positive for opiates, benzodiazepines, and Tricyclic Antidepressant (TCA), but she did not improve and remained obtunded. Subsequently, she was intubated to protect her airway. Further investigations revealed elevated ammonia level (193 $\mu \mathrm{mol} / \mathrm{L})$, low zinc level, normal vitamin B12 and folate level, negative immune and viral hepatitis panel, undetectable valproate and lithium level (Table 1), and mild hepatomegaly with fatty infiltration on CT of the abdomen. Blood and urine cultures were negative. Ascitic fluid analysis was negative for spontaneous bacterial peritonitis (SBP).

She received two pints of packed red blood cells, IV pantoprazole, D5\% fluid, lactulose/rifaximin via nasogastric tube, and vitamin $\mathrm{K}$ subcutaneous. Her mentation and serum ammonia $(115 \mu \mathrm{mol} / \mathrm{L})$ improved over the next day and she was extubated. But, over the next few days, she continued to have fluctuating mental status (in and out of confusion
TABLE 2: Special laboratory investigation panel.

\begin{tabular}{|c|c|c|}
\hline Lab test & Results & Ref. range \\
\hline \multicolumn{3}{|c|}{ Plasma amino acid profiles: } \\
\hline Alanine & 350 & $200-483 \mu \mathrm{mol} / \mathrm{L}$ \\
\hline Arginine & 130 & $43-407 \mu \mathrm{mol} / \mathrm{L}$ \\
\hline Asparagine & 131 & $31-64 \mu \mathrm{mol} / \mathrm{L}$ \\
\hline Aspartic acid & 5 & $1-4 \mu \mathrm{mol} / \mathrm{L}$ \\
\hline Beta-alanine & 3 & $<5 \mu \mathrm{mol} / \mathrm{L}$ \\
\hline Citrulline & 43 & $16-51 \mu \mathrm{mol} / \mathrm{L}$ \\
\hline Glutamine & 1363 & $428-747 \mu \mathrm{mol} / \mathrm{L}$ \\
\hline Glutamic acid & 55 & $10-97 \mu \mathrm{mol} / \mathrm{L}$ \\
\hline Glycine & 555 & $122-322 \mu \mathrm{mol} / \mathrm{L}$ \\
\hline Histidine & 129 & $60-109 \mu \mathrm{mol} / \mathrm{L}$ \\
\hline Homocysteine & $<1$ & $<1 \mu \mathrm{mol} / \mathrm{L}$ \\
\hline Hydroxyproline & 71 & $4-27 \mu \mathrm{mol} / \mathrm{L}$ \\
\hline Isoleucine & 27 & $34-98 \mu \mathrm{mol} / \mathrm{L}$ \\
\hline Leucine & 46 & $73-182 \mu \mathrm{mol} / \mathrm{L}$ \\
\hline Lysine & 359 & $119-233 \mu \mathrm{mol} / \mathrm{L}$ \\
\hline Methionine & 22 & $16-34 \mu \mathrm{mol} / \mathrm{L}$ \\
\hline Ornithine & 149 & $27-83 \mu \mathrm{mol} / \mathrm{L}$ \\
\hline Phenylalanine & 70 & $40-74 \mu \mathrm{mol} / \mathrm{L}$ \\
\hline Proline & 632 & $104-383 \mu \mathrm{mol} / \mathrm{L}$ \\
\hline Serine & 156 & $65-138 \mu \mathrm{mol} / \mathrm{L}$ \\
\hline Taurine & 43 & $31-102 \mu \mathrm{mol} / \mathrm{L}$ \\
\hline Tryptophan & 5 & $40-91 \mu \mathrm{mol} / \mathrm{L}$ \\
\hline Tyrosine & 46 & $38-96 \mu \mathrm{mol} / \mathrm{L}$ \\
\hline Valine & 73 & $132-313 \mu \mathrm{mol} / \mathrm{L}$ \\
\hline \multicolumn{3}{|c|}{ Serum carnitine levels: } \\
\hline T. carnitine & 88 & $31-67 \mathrm{nmol} / \mathrm{mL}$ \\
\hline F. carnitine & 61 & $25-55 \mathrm{nmol} / \mathrm{mL}$ \\
\hline \multicolumn{3}{|c|}{ Urine orotic acid level: } \\
\hline Ur. orotic acid & 2.3 & $0.4-1.2 \mathrm{mmol} / \mathrm{molcr}$ \\
\hline
\end{tabular}

T.: total; F.: free; Ur.: urine.

and delirium) and serum ammonia level (Figure 2). Blood hemoglobin remained stable after the first transfusion. Coagulopathy was corrected after vitamin K supplement. Despite standard treatment for hyperammonemia, her clinical condition deteriorated and she was reintubated.

At this stage, we considered alternative explanation and conducted plasma amino acid profile and urinary orotic acid level (Table 2) to explain the etiology of intractable hyperammonemia. On the 12th day of admission, she developed status epilepticus, which was controlled only with propofol infusion. Repeat CT of the head was consistent with diffuse cerebral edema (Figure 1(b)). Before the results of amino acid profile and urinary orotic acid level came back, she rapidly deteriorated clinically over the short period of time from status epilepticus and coma to multiorgan failure and subsequently died. With elevated urinary orotic acid and serum ornithine levels, normal/low-normal serum arginine and citrulline levels along with other findings, we concluded that her hyperammonemia might have resulted in unmasking of functional deficiency of urea cycle enzyme/s in 


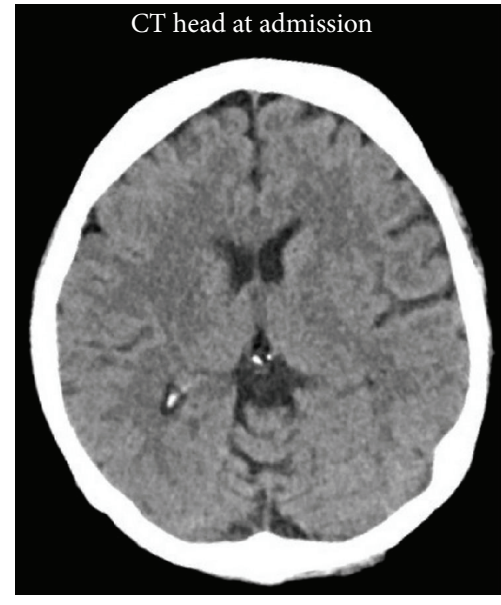

(a)

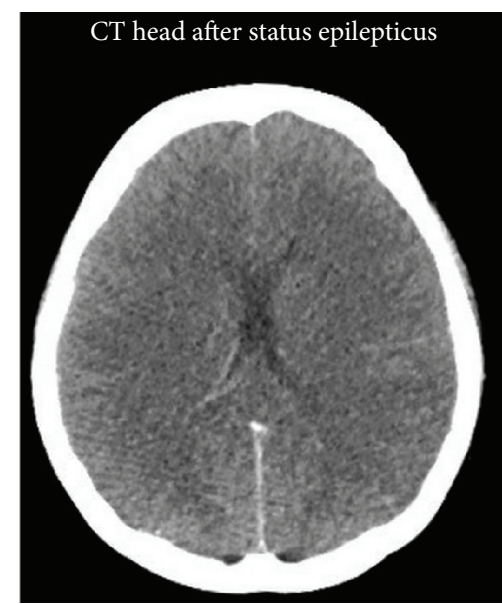

(b)

FIGURE 1: Computed tomography of the head at admission and at onset of status epilepticus. Computed tomography (CT) of the head (a) showed no remarkable findings on the day of admission and (b) showed diffused brain swelling consistent with cerebral edema on 12th day.

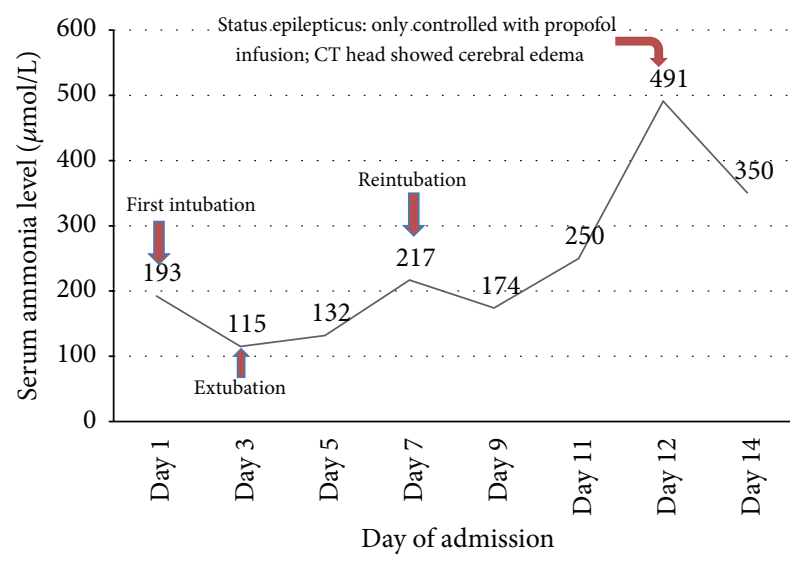

Figure 2: Graphical representation of serum ammonia level and associated events. Fluctuation of serum ammonia level during ICU course on this patient. Level of ammonia and mental status did not improve much with conventional treatment of hyperammonemia. The patient showed status epilepticus, which did not improve with midazolam and phenytoin and needed propofol drip to control the seizure. CT of the brain at that stage showed diffused cerebral edema.

this malnourished woman following bariatric surgery. With rapid clinical deterioration followed by death, confirmatory enzymes assay and DNA testing could not be done.

\section{Discussion}

Hyperammonemia is defined as an increase in the level of ammonia in the blood. Ammonia is a toxic by-product of protein and energy metabolism through biochemical transamination and deamination process in all body tissue. Ammonia is converted to urea (ureagenesis) via urea cycle (Figure 3) primarily in hepatocytes and is excreted through the kidneys and large intestine. Urea can be easily hydrolyzed to ammonia and carbon dioxide by enzyme urease. So, elevated serum ammonia may result from its increased production, absorption (from intestine or urinary tract), decreased elimination of ammonia, and/or impaired ureagenesis. Hyperammonemia is always a sign of insufficient nitrogen excretion as discussed above, but it does not always necessitate symptomatic presentation. The signs and symptoms of hyperammonemia are usually neurological from mild cognitive and psychomotor changes to altered level of consciousness and coma [1]. Serum ammonia levels above $200 \mu \mathrm{mol} / \mathrm{L}$ are reported to be associated with cerebral edema, herniation, and death [2].

It is imperative not only to diagnose early and manage efficiently but also to find the etiology of symptomatic hyperammonemia. Liver pathology, the most common cause of hyperammonemia, almost always presents with altered liver function tests. Hyperammonemia in the context of unremarkable (or normal) liver function tests becomes diagnostically challenging for physicians. The etiologies of nonhepatic hyperammonemia based on literature are summarized (Table 3). Hyperammonemia has been reported following lung and bone marrow transplantation, portosystemic shunts, ureterosigmoidostomy, chemotherapy of hematological malignancies, and solid organ tumors with 5-fluorouracil [3]. Infections with urease-producing bacteria such as Proteus mirabilis, Helicobacter pylori, Cornebacterium, Klebsiella, and Morganella species cause hyperammonemia presumably due to reabsorption of ammonia (generated from hydrolysis of urea) into the systemic circulation [4]. Hyperalimentation, valproic acid, and carnitine deficiency are reported to cause hyperammonemia [5-8]. In this patient, GI bleeding was initially considered for possible cause of hyperammonemia; however, serum ammonia level remained persistently high even after the treatment of GI bleeding. Elevated INR and aPTT were most likely secondary to vitamin $\mathrm{K}$ deficiency. Treatment with vitamin K improved the coagulopathy. All of the other above mentioned causes were essentially excluded with clinical history and relevant laboratory investigations. 


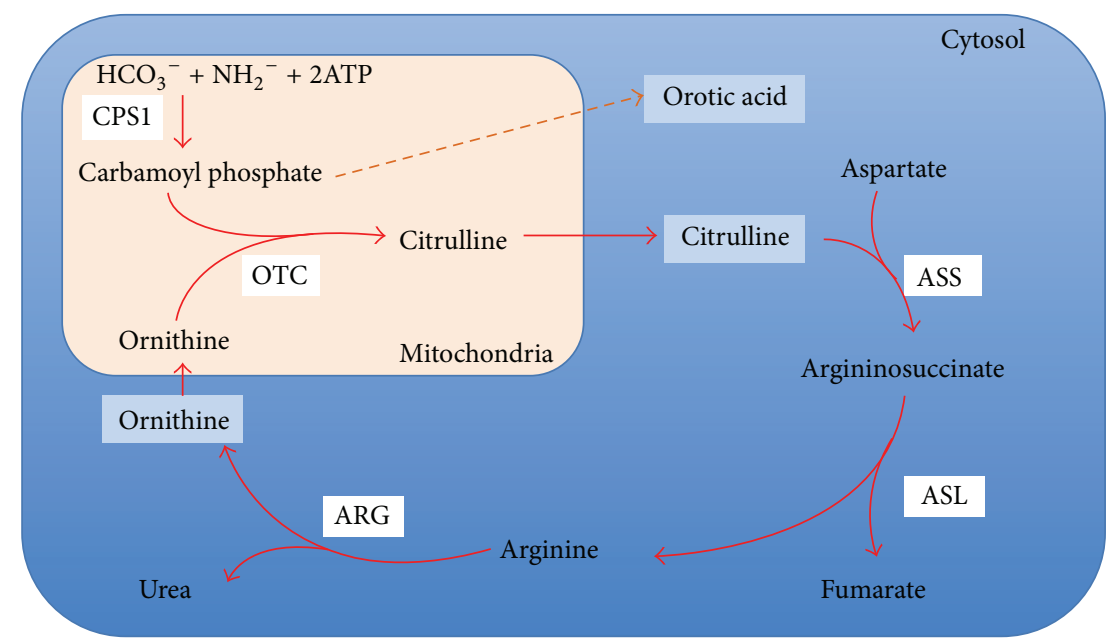

FIGURE 3: Schematic diagram of urea cycle and associated enzymes, CPS1: carbamoyl phosphate synthase 1; OTC: ornithine transcarbamylase; ARG: arginase; ASS: argininosuccinate synthetase; ASL: argininosuccinate lyase; ATP: adenosine triphosphate.

TABLE 3: Differential diagnosis of nonhepatic hyperammonemia based on [3-8].

\begin{tabular}{lll}
\hline SN & Ddx & Characteristics \\
\hline 1 & Medications & Valproic acid, 5-FU \\
\hline & & Urease-producing bacteria: \\
& Infections & (i) Proteus mirabilis \\
& & (ii) Helicobacter pylori \\
& (iii) Cornebacterium, Klebsiella, and Morganella species \\
\hline & & (i) Lung transplant \\
& Surgery & (ii) Bone marrow transplant \\
& & (iii) Ureterosigmoidoscopy \\
& & (iv) Portosystemic shunts \\
& Hyperalimentation & (v) Bariatric surgery
\end{tabular}
Errors in metabolism

\begin{tabular}{ll}
5 & (a) Fatty acid oxidation defects \\
& $\begin{array}{l}\text { (b) Urea cycle enzyme defects } \\
\text { (c) Amino acid disorders }\end{array}$ \\
\hline 6 & Gastrointestinal bleeding \\
\hline 7 & Carnitine deficiency
\end{tabular}

Inborn errors in metabolism such as fatty acid oxidation defects, amino acid disorders, and urea cycle disorders that cause hyperammonemia are usually present early in childhood [9, 10]. Fatty acid oxidation defects are usually associated with hypoglycemic episodes [11], while amino acid disorders are with metabolic acidosis and ketosis [12, 13]. Both hypoglycemia and metabolic acidosis were not reported in this patient.

Urea cycle disorders (UCDs), as a result of deficiency of or defects in enzymes, usually present with hyperammonemia causing severe morbidity and mortality [14]. Literatures have shown a manifestation of late onset of one or more enzyme functional deficiency/ies unmasking the genetic disorders of the urea cycle in patients after bariatric surgery [1518]. Markedly increased plasma glutamine, ornithine, and urinary orotic acid levels in the background of severe malnutrition and zinc deficiency may have led to unfolding of the functional deficiency of urea cycle enzyme/s leading to impaired ureagenesis and intractable hyperammonemia. Zinc deficiency can interfere with ornithine transcarbamylase (OTC) function $[19,20]$, which is possible in this patient. OTC deficiency, an X-linked disorder, is the most common inborn error of the urea cycle [21] and it usually has a fatal outcome soon after birth due to hyperammonemic coma. Heterozygous female may remain asymptomatic until the patient becomes acutely or chronically challenged by enough physiological stress. The recent gastrojejunal stent placement and decreased oral intake in chronically severe ProteinEnergy Malnutrition (PEM) state probably led to increased physiological stress and catabolism in our patient. Blind 
loop syndrome with bacterial overgrowth in the patient with RYGBP (mainly distal type) may lead to illness, decreased oral intake, and increased catabolism. Alternative routes of enteral feeding such as gastrostomy may be needed to keep up with metabolism during an illness in such patients. In this case, no further information on the type of RYGBP was available as the procedure was done in another institution. DNA analysis of urea cycle enzymes would have given more definite etiology, but it was not carried out. Around $20-30 \%$ of patients with OTC deficiency are not detected in DNA analysis [22].

The initial goal of treatment should be to reduce ammonia production and absorption and facilitate elimination [23]. Intravenous glucose infusion should be started to provide a source of energy and raise insulin secretion that halts the protein breakdown due to its anabolic property. With the same token, protein intake should be restricted. IV lipid can also be given in increased energy demand. Alternative pathway therapies with sodium benzoate, sodium phenyl butyrate, and arginine have been proposed because these promote the synthesis of nitrogen-containing metabolites with high urinary excretion rates as an alternative to urea to remove waste nitrogen from the body [24]. In cases of uncontrolled hyperammonemia, hemodialysis may be an effective treatment. Due to rapid clinical deterioration and hemodynamic instability, hemodialysis could not be done in our patient. The mainstays of long-term management are dietary protein restriction, arginine or citrulline supplements, and oral alternative pathway medication to facilitate nitrogen excretion. Reversal of bariatric procedure is considered for the failure of weight loss or other complications due to the bariatric surgery itself. The decision of reversal tends to be highly individualized [25]. Consultation with an experienced bariatric surgeon may benefit when a patient presents with the nutritional/metabolic complication of bariatric surgery. This case report contains certain limitations such as being unable to perform DNA tests for urea cycle enzymes, hemodialysis, and use of aggressive scavengers such as sodium benzoate for management of hyperammonemia. Even with optimum therapy, this clinical entity is still associated with high rate of mortality.

In conclusion, hyperammonemia encephalopathy following bariatric surgery in the context of normal liver function tests becomes diagnostically challenging for physicians. The exact mechanism of hyperammonemia in such patient is still not clear but more data are gradually emerging in the support of cause-effect relationship among the triad of hyperammonemia, nutritional complications following bariatric surgery, and functional deficiency of urea cycle enzymes. We emphasize the importance of considering secondary causes of hyperammonemia in an adult woman after bariatric surgery. Early diagnosis and aggressive management are the only keys to improving survival.

\section{Abbreviations}

ABG: Arterial blood gas

ALT: Alanine aminotransferase

aPTT: Activated partial thromboplastin time
AST: Aspartate aminotransferase

BUN: Blood urea nitrogen

CT: $\quad$ Computed tomography

D5\%: 5\% dextrose

DNA: Deoxyribonucleic acid

ED: Emergency Department

EKG: Electrocardiogram

GCS: Glasgow Coma Scale

GI: Gastrointestinal

HDL: High-density lipoprotein

INR: International normalized ratio

IV: Intravenous

OTC: Ornithine transcarbamylase

PEM: Protein-Energy Malnutrition

PRBCs: Pack red blood cells

RYGBP: Roux-en-Y Gastric Bypass Procedure

SBP: $\quad$ Spontaneous bacterial peritonitis

UCD: Urea cycle disorder.

\section{Competing Interests}

Authors of this case report declare no competing interests.

\section{References}

[1] R. K. Dhiman and Y. K. Chawla, "Minimal hepatic encephalopathy: time to recognise and treat," Tropical Gastroenterology, vol. 29, no. 1, pp. 6-12, 2008.

[2] D. Shawcross and R. Jalan, "The pathophysiologic basis of hepatic encephalopathy: central role for ammonia and inflammation," Cellular and Molecular Life Sciences, vol. 62, no. 19-20, pp. 2295-2304, 2005.

[3] L. Nott, T. J. Price, K. Pittman, K. Patterson, and J. Fletcher, "Hyperammonemia encephalopathy: an important cause of neurological deterioration following chemotherapy," Leukemia and Lymphoma, vol. 48, no. 9, pp. 1702-1711, 2007.

[4] M. Albersen, S. Joniau, H. Van Poppel, P.-J. Cuyle, D. C. Knockaert, and W. Meersseman, "Urea-splitting urinary tract infection contributing to hyperammonemic encephalopathy," Nature Clinical Practice Urology, vol. 4, no. 8, pp. 455-458, 2007.

[5] R. E. Grazer, J. M. Sutton, S. Friedstrom, and F. D. McBarron, "Hyperammonemic encephalopathy due to essential amino acid hyperalimentation," Archives of Internal Medicine, vol. 144, no. 11, pp. 2278-2279, 1984.

[6] D. M. Felig, S. W. Brusilow, and J. L. Boyer, "Hyperammonemic coma due to parenteral nutrition in a woman with heterozygous ornithine transcarbamylase deficiency," Gastroenterology, vol. 109, no. 1, pp. 282-284, 1995.

[7] D. G. Vossler, A. J. Wilensky, D. F. Cawthon et al., "Serum and CSF glutamine levels in valproate-related hyperammonemic encephalopathy," Epilepsia, vol. 43, no. 2, pp. 154-159, 2002.

[8] B. N. Limketkai and S. D. Zucker, "Hyperammonemic encephalopathy caused by carnitine deficiency," Journal of General Internal Medicine, vol. 23, no. 2, pp. 210-213, 2008.

[9] H. O. de Baulny, A. Slama, G. Touati, D. M. Turnbull, M. Pourfarzam, and M. Brivet, "Neonatal hyperammonemia caused by a defect of carnitine-acylcarnitine translocase," The Journal of Pediatrics, vol. 127, no. 5, pp. 723-728, 1995.

[10] N. Longo, C. A. di San Filippo, and M. Pasquali, "Disorders of carnitine transport and the carnitine cycle," American Journal 
of Medical Genetics-Seminars in Medical Genetics, vol. 142, no. 2, pp. 77-85, 2006.

[11] C. A. Stanley, "New genetic defects in mitochondrial fatty acid oxidation and carnitine deficiency," Advances in Pediatrics, vol. 34, pp. 59-88, 1986.

[12] J. M. Kwon and K. E. D’Aco, "Clinical neurogenetics: neurologic presentations of metabolic disorders," Neurologic Clinics, vol. 31, no. 4, pp. 1031-1050, 2013.

[13] J. N. Labuzetta, J. Z. Yao, D. L. Bourque, and J. Zivin, "Adult nonhepatic hyperammonemia: a case report and differential diagnosis," American Journal of Medicine, vol. 123, no. 10, pp. 885-891, 2010.

[14] O. Braissant, "Current concepts in the pathogenesis of urea cycle disorders," Molecular Genetics and Metabolism, vol. 100, supplement 1, pp. S3-S12, 2010.

[15] K. R. Bergmann, J. McCabe, T. R. Smith, D. J. Guillaume, K. Sarafoglou, and S. Gupta, "Late-onset ornithine transcarbamylase deficiency: treatment and outcome of hyperammonemic crisis," Pediatrics, vol. 133, no. 4, pp. e1072-e1076, 2014.

[16] A. Z. Fenves, O. A. Shchelochkov, and A. Mehta, "Hyperammonemic syndrome after Roux-en-Y gastric bypass," Obesity, vol. 23, no. 4, pp. 746-749, 2015.

[17] W. T. Hu, O. H. Kantarci, J. L. Merritt II et al., "Ornithine transcarbamylase deficiency presenting as encephalopathy during adulthood following bariatric surgery," Archives of Neurology, vol. 64, no. 1, pp. 126-128, 2007.

[18] J. Estrella, G. Yee, B. Wilcken, M. Tchan, and M. Talbot, "Hyperammonemic encephalopathy complicating bariatric surgery: a case study and review of the literature," Surgery for Obesity and Related Diseases, vol. 10, no. 3, pp. e35-e38, 2014.

[19] L. C. Kuo, W. N. Lipscomb, and E. R. Kantrowitz, “Zn(II)induced cooperativity of Escherichia coli ornithine transcarbamoylase," Proceedings of the National Academy of Sciences of the United States of America, vol. 79, no. 7 I, pp. 2250-2254, 1982.

[20] E. Aquilio, R. Spagnoli, D. Riggio, and S. Seri, "Effects of zinc on hepatic ornithine transcarbamylase (OTC) activity," Journal of Trace Elements and Electrolytes in Health and Disease, vol. 7, no. 4, pp. 240-241, 1993.

[21] C. L. Pridmore, J. T. R. Clarke, and S. Blaser, "Ornithine transcarbamylase deficiency in females: an often overlooked cause of treatable encephalopathy," Journal of Child Neurology, vol. 10, no. 5, pp. 369-374, 1995.

[22] S. Yamaguchi, L. L. Brailey, H. Morizono, A. E. Bale, and M. Tuchman, "Mutations and polymorphisms in the human ornithine transcarbamylase (OTC) gene," Human Mutation, vol. 27, no. 7, pp. 626-632, 2006.

[23] A. S. Clay and B. E. Hainline, "Hyperammonemia in the ICU," Chest, vol. 132, no. 4, pp. 1368-1378, 2007.

[24] V. Walker, "Severe hyperammonaemia in adults not explained by liver disease," Annals of Clinical Biochemistry, vol. 49, no. 3, pp. 214-228, 2012.

[25] E. Chousleb, S. Patel, S. Szomstein, and R. Rosenthal, "Reasons and operative outcomes after reversal of gastric bypass and jejunoileal bypass," Obesity Surgery, vol. 22, no. 10, pp. 1611-1616, 2012. 


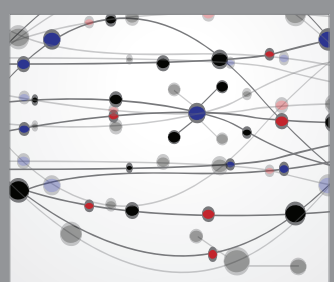

The Scientific World Journal
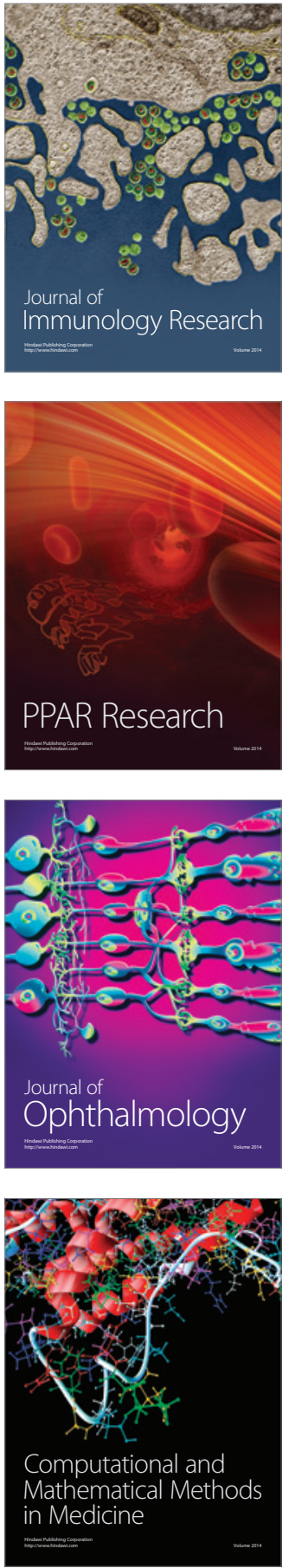

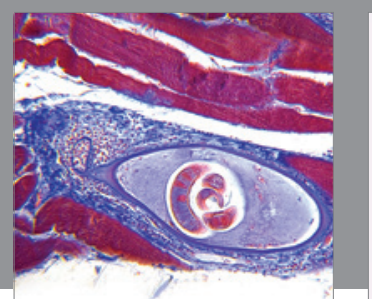

Gastroenterology Research and Practice

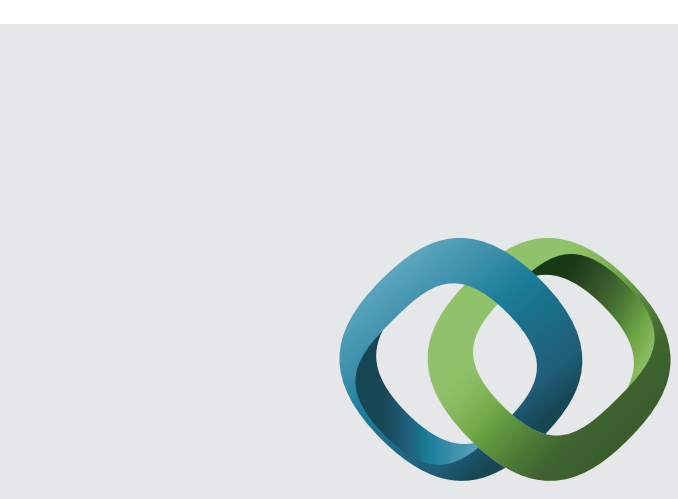

\section{Hindawi}

Submit your manuscripts at

http://www.hindawi.com
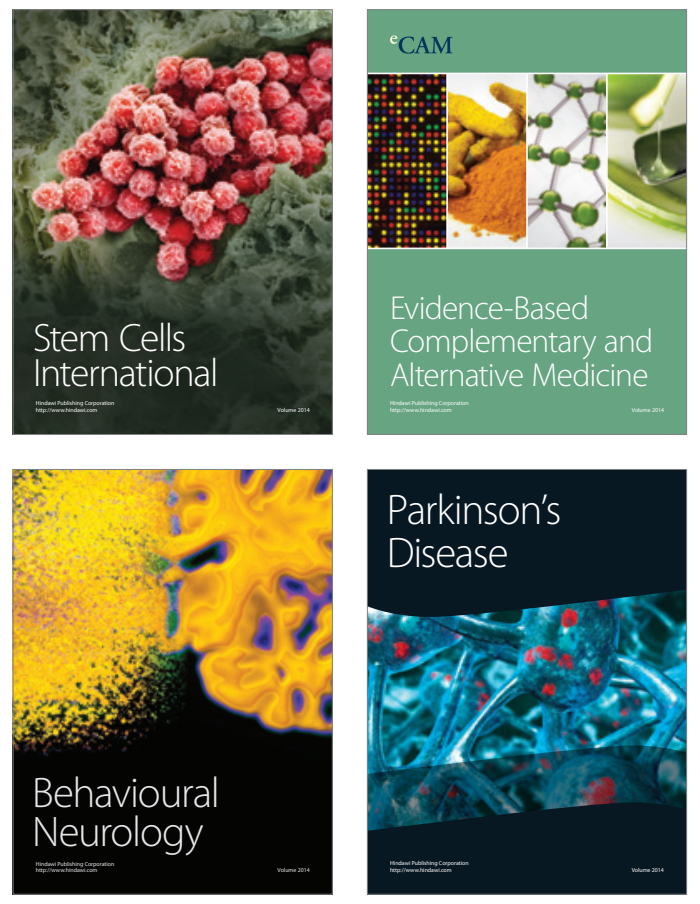
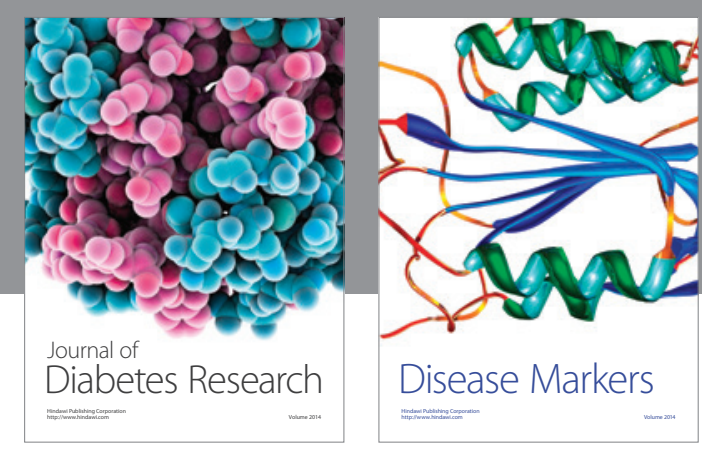

Disease Markers
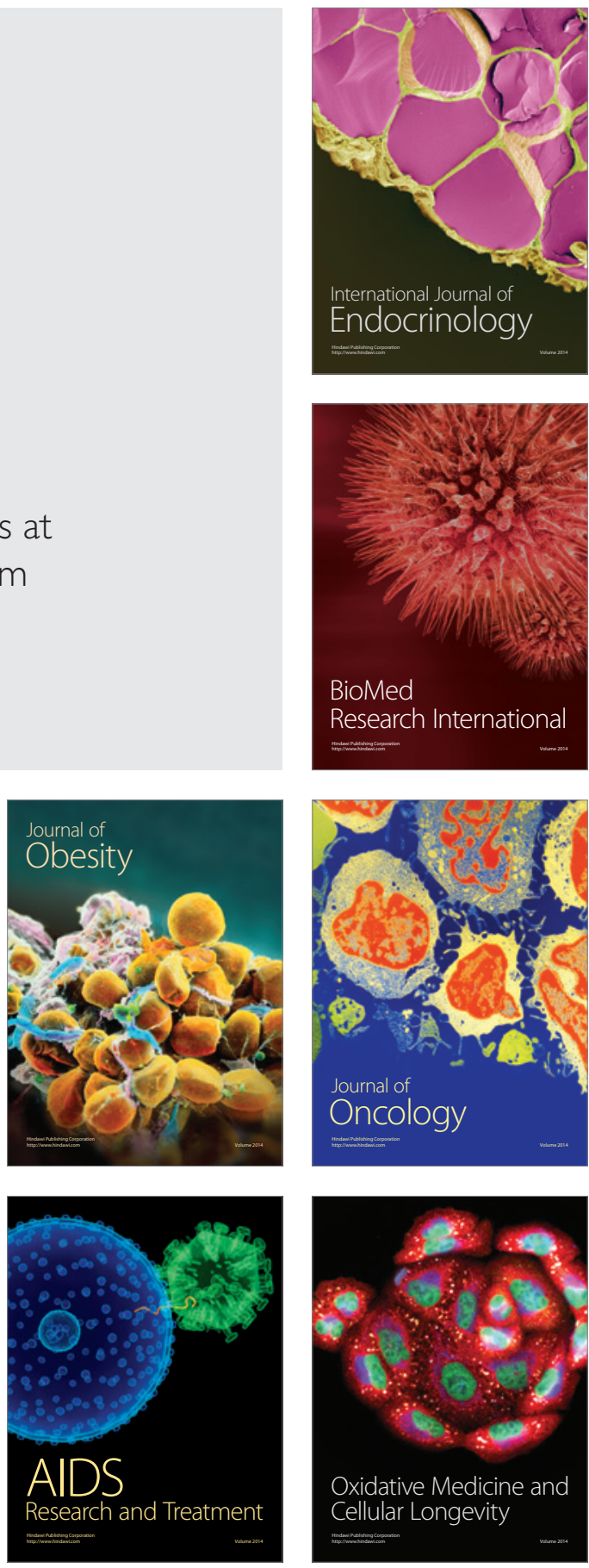